\title{
Large-scale macroinvertebrate assemblage patterns from least-disturbed wadeable stream sites across the 48 contiguous US states
}

\author{
W.J. Gerth ${ }^{(1)}$, A.T. Herlihy ${ }^{(1), \star}$, J.C. Sifneos ${ }^{(2)}$
}

Received October 24, 2012

Revised January 16, 2013

Accepted January 20, 2013

\section{ABSTRACT}

Key-words: We quantified the patterns in macroinvertebrate assemblages and their least-disturbed, associated environmental gradients from 457 least-disturbed wadeable macroinvertebrate stream sites across the 48 contiguous United States sampled as part assemblages, stream classification, indicator taxa, traits of US EPA's National Wadeable Stream Assessment. The majority of the variation in assemblage composition at the finest taxonomic resolution was related to substrate size, \%fastwater habitat, water chemistry, as well as east-west geographic position and elevation. Sites were classified into 5 groups with cluster analysis, and group membership was predicted from environmental data using classification tree analysis (CTA). CTA correctly classified $69.1 \%$ of test sites and indicated that groups were distinguished by east-west location, and by factors distinguishing mountain streams from lowland/plains streams. Eastern and western groups that had similar environmental characteristics had very similar coarse scale taxa composition and convergent taxa traits. Ordinations confirmed that composition patterns using coarse level taxa resolution and taxa traits no longer reflected geographic distinctions, but were only related to non-geographic environmental factors. However, composition patterns based on traits, coarse taxa, and macroinvertebrates identified to the finest practical level were all correlated with the same dominant non-geographic environmental gradients.

\section{RÉSUMÉ}

Schémas de répartition à large échelle des assemblages de macro-invertébrés de sites de rivières échantillonnables à gué dans 48 états US contigus
Mots-clés :
Nous avons quantifié les schémas de répartition dans les assemblages de macro-
site
de référence, assemblages
de macro-
invertébrés, classification de rivières, invertébrés et leurs gradients environnementaux associés à partir de 457 sites les moins perturbés possibles dans des cours d'eau échantillonnables à gué de 48 États américains contigus échantillonnés dans le cadre de I'US EPA's National Wadeable Stream Assessment. La majeure part de la variation de la composition des assemblages à la résolution taxonomique la plus fine est liée à la taille du substrat, au \% d'habitat d'eau vive, à la chimie de l'eau, ainsi que d'est en ouest à la position géographique et à l'altitude. Les sites ont été classés en 5 groupes avec une analyse par regroupement, et l'appartenance au groupe a été prédite à partir de données sur l'environnement en utilisant l'analyse par arbre de classification (CTA). CTA a classé correctement $69,1 \%$ des sites test et a montré que les groupes

(1) Department of Fisheries \& Wildlife, Nash 104, Oregon State University, Corvallis, OR 97331, USA

(2) Department of Statistics, Oregon State University, Corvallis, OR 97331, USA

* Corresponding author: alan.herlihy@oregonstate.edu 
taxons indicateurs, traits de vie sont distingués par la localisation est-ouest, et par des facteurs qui distinguent les cours d'eau de montagne, des rivières de basse altitude/plaines. Les groupes de l'est et de l'ouest qui ont les mêmes caractéristiques environnementales ont une composition en taxons définis à un niveau grossier très similaire et des traits de vie convergents. Les ordinations confirment que les schémas de composition faits à un niveau de résolution grossier des taxons et les traits des taxons ne reflètent plus des distinctions géographiques mais sont seulement reliés à des facteurs environnementaux non géographiques. Toutefois, les schémas de composition basés sur des traits, des taxons grossiers, et les macro-invertébrés identifiés au niveau le plus fin possible ont tous été corrélés avec les mêmes gradients environnementaux dominants non géographiques.

\section{INTRODUCTION}

One of the main goals in ecology is to understand the distributions and abundances of organisms. Local assemblages of stream organisms are structured by regional species pools which must pass through a set of hierarchically-scaled filters at levels ranging from the watershed to microhabitat (Poff, 1997; Malmqvist, 2002; Heino et al., 2007). Regional species pools are in turn related to regional climate and physiography and are the result of dispersal, isolation, extinction, and speciation that has occurred in the past. Thus, a multiscale interaction of environmental factors and biota has occurred over time to develop the local assemblages we have today.

Within the last 20-30 years, there has been an increase in the use of macroinvertebrates as indicators of stream ecological condition. Data collected for biological monitoring and assessment of rivers and streams have also been useful to increase our understanding of the natural interacting local, landscape, and regional environmental factors influencing invertebrate assemblage composition. As the spatial extent of sample and data collection expanded, it was noted that perceptions of which environmental factors are most strongly related to assemblage composition depend in part on the spatial extent of observation (Marchant et al., 1999; Sandin and Johnson, 2004; Bonada et al., 2005; Johnson et al., 2007). However, understanding the major factors relating to assemblage composition at a broad scale can give context to our understanding of factors controlling assemblages at smaller scales of observation.

Regional or national macroinvertebrate assemblage patterns in streams least disturbed by human activities have been examined in Europe (Wright et al., 1984; Heino et al., 2003; Lorenz et al., 2004; Sandin and Johnson, 2004), Australia (Marchant et al., 1999; Smith et al., 1999; Turak et al., 1999), and North America (Waite et al., 2000). Examinations of assemblage patterns at even larger spatial scales are not often attempted because of the difficulty of collecting a large number of samples over a wide area, and collecting and analyzing samples and data in a consistent manner. An examination of macroinvertebrate patterns across the European Union (land area approximately $4500000 \mathrm{~km}^{2}$ ) was attempted (Verdonschot and Nijboer, 2004), but sample locations were clumped, large spatial gaps existed, and data quality varied by country. Subsequent sampling and analyses filled in many gaps, but countries and regions were still unrepresented (Furse et al., 2006; Verdonschot, 2006b).

In addition to being affected by spatial scale, our perceptions about factors related to macroinvertebrate assemblages can be influenced by whether assemblage members are categorized taxonomically or by their functional traits. For studies extending over large areas, analyses using taxa are expected to more strongly reflect regional environmental factors and differences in regional taxon pools; traits-based analyses should reflect local habitat templates and be relatively insensitive to regional factors (Heino et al., 2007; Hoeinghaus et al., 2007). As a result, if groups of sites from different regions have similar environmental characteristics, we would expect them to be taxonomically distinct, but less distinguishable or convergent in their functional traits (Lamouroux et al., 2002). Further if assemblages are categorized taxonomically, varying the taxonomic resolution might also influence our perception of 
assemblage patterns (Hawkins et al., 2000a; Waite et al., 2000; Lenat and Resh, 2001; Lorenz et al., 2004; Verdonschot, 2006a). Reducing the taxonomic resolution of macroinvertebrate data might also result in convergence of groups of spatially separated sites with similar environmental characteristics, as with functional traits, but this has not been demonstrated in previous studies.

The purpose of this study was to elucidate the major environmental gradients associated with variation in assemblage composition at least-disturbed sites across the 48 contiguous US states (land area approximately $8000000 \mathrm{~km}^{2}$ ). Further, we wanted to look for natural groupings of assemblage-types, describe them in terms of indicator taxa, associated environmental variables, and geographic distribution, and determine how accurately we could predict assemblage group membership using geographic and environmental variables. Finally, we wanted to know if assemblage-based groups defined using invertebrates identified to the finest practical level were convergent at coarser scales of taxonomic resolution and/or when taxa traits were used.

\section{MATERIALS AND METHODS}

\section{> DATABASE COMPILATION}

We compiled a database of macroinvertebrate and environmental data from least-disturbed wadeable stream sites throughout the 48 contiguous US states. Data for our study were taken from the US Environmental Protections Agency's (EPA) National Wadeable Stream Assessment (WSA). The WSA was a product of two surveys. In the twelve western states, flowing waters (streams and rivers) were sampled during summer 2000-2004 as part of EPA's Environmental Monitoring and Assessment Program's (EMAP) Western Pilot (Stoddard et al., 2005). Within this set of western sites, there were 841 probability sites that were wadeable (could be sampled safely by field crews wading the stream). In a second survey, another 551 wadeable stream probability sites were sampled from the 36 Eastern states in summer 2004. All probability sites were selected using the randomized EMAP sampling design from the digital stream network depicted on 1:100 000 scale USGS topographic maps (Herlihy et al., 2000; Stevens and Olsen, 2004) to insure that the samples were representative of the surveyed regions. In addition, during the same survey period, 333 hand-picked streams in the West and 143 hand-picked streams in the East were sampled in an attempt to augment the number of least-disturbed sites. Both hand-picked and probability sites were used as potential leastdisturbed sites for our analyses if they passed screening criteria. Identical field sampling and lab protocols were used for all data collection (Peck et al., 2006).

Water chemistry and physical habitat data were used to identify the least-disturbed sites in each ecoregion as has been done in previous EMAP studies (Waite et al., 2000; Klemm et al., 2003). The screening process involves defining a set ecoregion-specific criteria values indicative of disturbance and any site that fails to meet all criteria was not considered a leastdisturbed reference site. Whittier et al. (2007) describe in detail the process for defining leastdisturbed sites for the EMAP-West survey. For the eastern stream sites, a similar process was used to identify least-disturbed sites based on acid neutralizing capacity, sulfate, chloride, total nitrogen, total phosphorus, turbidity, \% fine sediment, EMAP riparian disturbance index, and EPA rapid bioassessment protocol habitat score as detailed in Herlihy et al. (2008). For our analyses, if sites were sampled several times, only data from the first sample visit were included and sites with macroinvertebrate samples with fewer than 150 invertebrates identified and counted were also deleted. The result was a group of 460 least-disturbed sample sites with a fairly good distribution of sites across this portion of North America.

We chose to use WSA data because all invertebrate samples were collected in a similar manner. This was important because we wanted to insure that differences between samples were representative of difference between sites, not differences between sampling methods. In the WSA, sample reaches consisted of a length of stream equal to 40 times the mean wetted stream width (minimum of $150 \mathrm{~m}$ ) delineated around the randomly selected 
stream sample point. Within each reach, 11 equidistant transects perpendicular to the direction of flow were established. Benthic macroinvertebrates were collected at each transect with a kick net (595- $\mu \mathrm{m}$ mesh). To determine the sampling location within each transect, the channel width was visually divided into thirds. At the 1st sample transect (furthest downstream), 1/3 of the channel width was randomly chosen, and invertebrates were collected from the center of this channel section. Collection location at subsequent transects was determined by systematically alternating the channel section sampled from the random start at the 1st transect. A reachwide composite sample for each site was collected by combining the $0.09-\mathrm{m}^{2}$ kick-net samples from each of the 11 evenly spaced transects. In the laboratory, each macroinvertebrate sample was placed in a sorting pan with a numbered grid, and squares from which organisms were sorted were chosen at random. Squares were chosen and sorted until 500 organisms were counted. The entire sample was sorted if there were fewer organisms than the target count.

WSA data were also useful because a relatively consistent set of local environmental data were collected along with the macroinvertebrate samples, allowing for a comprehensive view of environmental variation among sites. Water chemistry and physical habitat data were collected at each site using EMAP field protocols (Peck et al., 2006). For our analyses, water chemistry variables included concentrations of total suspended solids, dissolved organic carbon, total nitrogen, total phosphorus, conductivity, acid neutralizing capacity, sulfate, and chloride. Physical habitat variables included geometric mean substrate size, mean wetted width, mean thalweg depth, percent fast water habitat, riparian vegetation cover, and stream slope. Additional geographic data used in our analyses included site latitude and longitude and watershed area. In addition, site elevation was determined using 30-m digital elevation models (DEMs) and mean summer air temperature and average annual precipitation were extracted from PRISM data layers (Daly et al., 2002).

Macroinvertebrate samples were enumerated and identified by different laboratories over multiple years. Extensive laboratory quality assurance (QA) was conducted as part of the WSA (Stribling et al., 2008). 10\% of the samples were randomly selected for reidentification and enumeration. Percent differences in enumeration were small $(<3 \%)$. The initial QA goal for interlaboratory percent taxonomic difference (PTD) was 15\% and the first round of QA samples had a PTD of $21 \%$. Corrective actions were implemented to improve consistency among labs and a second round of QA samples showed a PTD of 14\%. Differences in identification were at the genus level, individuals were almost always correctly identified to family.

In terms of overall target taxonomic resolution, macroinvertebrates were identified to genus except for Oligochaetes and Arachnids (to family) and Nematodes and Platyhelminthes (to phylum). Small or damaged individuals were identified to coarser levels leading to some taxonomic level inconsistencies across samples. For example, certain families had a large number of individuals not identified to genus in all samples. To increase taxonomic level consistency across samples, we lumped up taxa identifications in all samples to a coarser level when only a certain proportion of samples had individuals identified to finer levels of resolution. We did this by starting at the phylum level and determining at how many samples a phylum occurred in the database. If more than $15 \%$ of the samples with the phylum present did not have any individuals in that phylum identified to class level, then these data were merged to the phylum level. The same $15 \%$ rule was applied at the class level, and this process was followed through the order, family, and genus levels until the taxonomic resolution to be used was determined for all taxa in all samples. The final database list contained 527 operational taxonomic units (OTUs), with $78 \%$ of the OTUs at the genus level.

Before conducting any analyses, data were further standardized by randomly picking 300 organisms or all of the organisms if there were fewer than 300 individuals. After doing this, $90 \%$ of samples had an exact count of 300 organisms, and $10 \%$ of sites had counts between 150 and 300 organisms counted. OTU abundances were then expressed as relative abundances. Both of these modifications had the effect of reducing the influence of differences in the total number of organisms counted in each sample. We screened sites using an outlier analysis (PC-ORD, version 4.41, MjM Software, Gleneden Beach, Oregon) with Bray-Curtis 
distance measures. This analysis calculates the average distance of each site from every other site. A frequency distribution of pair-wise distances is constructed and outliers greater than 2 standard deviations from the overall average distance are flagged. Three sites were flagged that had low taxonomic richness and high dominance by one or two taxa. Because these sites were unusual for least-disturbed sites, we eliminated them from the database. In addition, we removed rare taxa. Excluding rare species that add noise often facilitates extracting patterns with multivariate analyses. Following the rule of thumb proposed by McCune and Grace (2002), we deleted taxa that were present in fewer than $5 \%$ of the sites. Removal of rare taxa reduced the number of OTUs analyzed from 527 to 191. All multivariate analyses using OTUs were then conducted on this screened matrix of 457 sites by 191 OTUs.

Because we also wanted to examine how OTU assemblage patterns were related to patterns revealed using coarse taxonomic groups and traits, we needed to convert our screened site by OTU matrix to site by coarse taxon and site by taxon trait matrices. We constructed the new matrices using matrix multiplication (PC-ORD, version 4.41, MjM Software, Gleneden Beach, Oregon). For coarse taxa, we categorized each OTU into one of six categories (Diptera, Ephemeroptera, Plecoptera, Trichoptera, other insects, and non-insects), and made an OTU by coarse taxon group matrix.

We used the same approach to characterize sites in terms of taxonomic traits. We used 8 traits that are among the most independent and least phylogenetically constrained; voltinism (semi, uni, or multi), occurrence in drift (strong, rare, or common), shape (streamlined or not), size at maturity (small, medium, or large), rheophily (deposition, erosional, or both), thermal preference (cold, cool, or warm), habit (burrow, climb, sprawl, cling, swim, or skate), and trophic habit (collector-gatherer, collector-filterer, herbivore, predator, or shredder) using the states as described in Poff et al. (2006). These types of traits are expected to be the most responsive to local selection and least affected by differences in regional taxa pools. In total, for the 8 traits there were 28 trait states and taxa were assigned a single trait state per trait based on information in Poff et al. (2006). When taxa that occurred in our database were not found in Poff et al. (2006), trait states were assigned using additional information in Merritt et al. (2008), Thorp and Covich (2001) or best professional judgement.

\section{> DATA ANALYSES}

\section{Assemblage composition and environmental gradients}

Invertebrate assemblage similarity patterns based on OTU data were explored using nonmetric multidimensional scaling (NMS) ordination with Bray-Curtis dissimilarity measures on proportionate abundance data using PC-ORD. NMS is a nonparametric ordination technique that is one of the most robust methods for exploring biological community data (McCune, 1994; Cao et al., 1996). Dimensionality of the ordination solution was determined using the scree test (Kruskal and Wish, 1978) to assess the point at which additional axes provided little improvement in fit (stress reduction). Before correlations between environmental/geographic variables and axes scores were determined, environmental data were log-transformed (or arcsin square root transformed for percentage data) when necessary to reduce skewness or to make distributions more normal. Strong correlations of axis scores with relative abundances of individual OTUs, macroinvertebrate metrics, and environmental variables $(r \geq 0.4)$ were tabulated.

\section{Defining and describing assemblage-based groups}

Groups or clusters of sites with distinctive OTU-level invertebrate assemblages were defined using cluster analysis (PC-ORD, version 4.41, MjM Software, Gleneden Beach, Oregon). We used the flexible-beta linkage method (beta $=-0.25$ ) with the Bray-Curtis distance measure. The flexible-beta linkage with beta $=-0.25$ is a recommended method because it produces minimal distortion during the joining of groups (McCune and Grace, 2002). 
To determine the macroinvertebrate OTUs contributing to the distinctive nature of the assemblage-based groups, we conducted indicator species analysis (Dufrêne and Legendre, 1997). Taxon indicator values were calculated for each group as the product of percent faithfulness (all sites in the cluster should contain the taxon) and percent exclusiveness (the taxon should only be in the cluster and not others). Indicator values ranged from $0 \%$ (no indication) to $100 \%$ (perfect indication). A perfect score would indicate that the taxon is both $100 \%$ exclusive and faithful to that particular cluster. We also used PC-ORD to calculate the statistical significance of the percent indication for each OTU using a Monte Carlo test with 1000 simulations after randomly assigning sites to groups. The type I error ( $p$-value) for each OTU is the proportion of times that the percent indication in the random simulations exceeds the observed percent indication in the data (McCune and Grace, 2002). With 1000 simulations, the lowest possible $p$-value is 0.001 (the observed percent indication is greater than all of the random simulations).

We examined the dendrogram from the cluster analysis and evaluated groups formed when the dendrogram was pruned at points forming from 2 to 30 groups. Indicator species analyses for the 2 to 30 groups were used to determine the optimal prune point. Following the suggestion of Dufrêne and Legendre (1997), we calculated the mean $p$-value for all OTUs from the indicator species analysis and plotted it as a function of increasing number of groups. The optimal prune point in terms of the ability of indicator taxa to distinguish among groups is that with the lowest mean $p$-value. We also evaluated the homogeneity of sites within these optimal groups by calculating the mean within-group Bray-Curtis similarity.

OTUs characteristic of optimal groups were determined with indicator species analysis. To assess the spatial distribution of sites in these assemblage-based groups, sites were plotted by group on a map of the US. Environmental and geographic variables distinguishing groups were determined by examining box plots.

\section{Predicting assemblage-based group membership}

Cluster membership was predicted from environmental and geographic variables using classification tree analysis (CTA). Predicted versus observed matrices of the results provided an overall classification rate, as well as probabilities associated with how well each cluster group was predicted. We constructed the model using $67 \%$ of the data. The remaining $33 \%$ were used to validate the model. CTA is a nonparametric method for data analysis, with models fit by binary recursive partitioning of the data. We used the package rpart in $\mathrm{R}$ version 2.4.1. The data set is split into two groups by minimizing the impurity of the 2 groups according to the Gini splitting rule. The procedure is repeated until all nodes have pure class membership, the nodes have some minimum size, or some other stopping rule is applied (either during the growing process or after, e.g., pruning).

\section{Comparisons of OTU, trait, and coarse taxon patterns}

Two methods were used to compare OTU, trait and coarse taxon patterns. First, assemblagebased cluster groups formed using OTU data were compared to each other in terms of coarse-level taxonomic composition and in terms of assemblage traits. The purpose of these comparisons was to see if OTU-based assemblage groups would converge when these other ways of categorizing assemblages were used. We especially were interested to know if there were OTU-based groups that were spatially separated (i.e. had potentially different regional taxon pools), but otherwise had similar environmental conditions, and if coarse taxon and/or trait state relative abundances would reflect the environmental similarity among such groups. For the comparison using coarse-level taxonomy, site coarse taxon relative abundances were averaged for each OTU-based cluster group, and cluster group averages were examined graphically with a stacked bar plot. For the trait comparison, medians and interquartile ranges of trait state relative abundances were determined for each OTU-based cluster group, and these were tabulated for selected trait states. 
Table I

Sample percentiles of stream characteristics for the 457 streams in the national least-disturbed site database.

\begin{tabular}{|c|c|c|c|c|c|}
\hline Variable & 10th & 25th & Median & 75th & 90th \\
\hline Watershed area $\left(\mathrm{km}^{2}\right)$ & 3.1 & 10.4 & 36.4 & 118.8 & 355.4 \\
\hline Mean wetted width (m) & 1.8 & 3.0 & 4.9 & 8.7 & 15.1 \\
\hline Mean thalweg depth $(\mathrm{cm})$ & 14 & 21 & 31 & 47 & 63 \\
\hline Channel slope (\%) & 0.4 & 1.0 & 1.8 & 3.9 & 8.8 \\
\hline$\%$ fast water habitat & 2 & 13 & 40 & 67 & 83 \\
\hline$\%$ sand + silt substrate & 3 & 7 & 18 & 40 & 73 \\
\hline Conductivity $\left(\mu \mathrm{S} \cdot \mathrm{cm}^{-1}\right)$ & 26 & 46 & 111 & 382 & 859 \\
\hline Suspended solids $\left(\mathrm{mg} \cdot \mathrm{L}^{-1}\right)$ & 0.2 & 0.7 & 2.2 & 5.5 & 11.9 \\
\hline Nitrate-N ( $\mu$ eq. $\mathrm{L}^{-1}$ ) & 0.0 & 0.4 & 3.5 & 9.3 & 24.2 \\
\hline Total phosphorus $\left(\mu \mathrm{g} \cdot \mathrm{L}^{-1}\right)$ & 1.8 & 3.6 & 10.0 & 21.0 & 55.7 \\
\hline Elevation (m) & 167 & 308 & 647 & 1362 & 2007 \\
\hline Mean annual precipitation* $(\mathrm{mm})$ & 423 & 566 & 942 & 1174 & 1526 \\
\hline Mean August air temperature ${ }^{*}\left({ }^{\circ} \mathrm{C}\right)$ & 14.2 & 17 & 19.6 & 22 & 24.9 \\
\hline
\end{tabular}

*Denotes data from PRISM data layers (Daly et al., 2002).

The same NMS ordination procedure used to analyze the OTU assemblage data was used to explore patterns in assemblage trait states and in assemblage composition based on coarse taxonomic groupings. Again, the number of axes included was determined using the scree test (Kruskal and Wish, 1978). These two ordinations were compared with the one previously run to examine OTU-based assemblage patterns and relationships with environmental variables. To facilitate comparisons, each ordination was graphically rotated to maximize correlations of Axis 1 scores with the logarithm of mean substrate particle size. Graphical rotation affects neither the position of sites relative to one another in the ordination space nor the strength of correlations with environmental variables, but merely rotates the cloud of sample points within the frame of the axes and changes the direction of correlations with environmental variables (McCune and Grace, 2002). Ordinations showing the two axes explaining the majority of variation in site dissimilarity matrices were plotted. In each ordination, sites were coded according to their membership in OTU-based assemblage groups from cluster analysis, and positions and overlap of these groups in the 3 ordinations were examined. In addition, continuous environmental variables most highly correlated with ordination site coordinates $(|r|>0.45)$ were included in joint plots with vectors representing the strengths and directions of correlations. The numbers and types of correlated environmental variables were compared for the three ordinations.

\section{RESULTS}

Wadeable streams in our database exhibited the range of environmental conditions that could be expected for sites over such a broad geographic area (Table I). Watershed areas of sample sites ranged from 0.2 to over $10000 \mathrm{~km}^{2}$, with sites having the largest drainage areas located in more arid regions. Slopes ranged from $<0.1 \%$ to $34.9 \%$, with low slope sites predominantly in plains or valley regions and high slope sites from mountainous regions. Sites also varied in substrate composition and concentrations of suspended and dissolved materials.

In the full dataset, before rare taxa were eliminated, there were 527 different macroinvertebrate OTUs at the 457 sites. Richness at individual sites ranged from 17 to 78 taxa, with an average of 46 taxa per site. Oligochaete worms and aquatic mites were collected at over $80 \%$ of the sites, and the chironomid Polypedilum, and the mayfly Baetis were found at over $70 \%$ of sites. Other OTUs found at over $55 \%$ of the sites were Ceratopogonidae, Simuliidae, Leptophlebiidae, Tanytarsus, Empididae, Micropsectra, Thienemannimyia, and Eukiefferiella. 


\section{Table II}

Individual macroinvertebrate taxa, macroinvertebrate metrics, and environmental/geographic variables most highly correlated $(r \mid>0.4)$ with the NMS ordination axis scores. Values in parentheses are Pearson's correlation coefficients.

\begin{tabular}{|l|c|c|}
\hline Axis 1 & Axis 2 & Axis 3 \\
\hline Taxa & Baetis (+0.42) & \\
$\quad$ Chyacophila (+0.52) & Stenonema (-0.43) & \\
Baetis (+0.42) & & \\
Epeorus (+0.41) & & \\
Oligochaeta (-0.44) & & \\
Procladius (-0.44) & & \\
Dubiraphia (+0.44) & & \\
Caenis (-0.48) & & \\
\hline Macroinvertebrate metrics & & \\
EPT richness (+0.73) & & \\
\%EPT (+0.71) & & \\
\%non-insects (-0.45) & & \\
\hline Environmental variables & \\
\% fastwater (+0.70) & Longitude (+0.71) & \\
Mean substrate size (+0.67) & Elevation (+0.65) & \\
Stream slope (+0.59) & Mean summer air temp (-0.56) & \\
Riparian woody cover (+0.42) & & \\
Suspended solids (-0.49) & & \\
Watershed area (-0.49) & & \\
Acid neutralizing capacity (-0.51) & & \\
Mean summer air temp (-0.57) & & \\
Dissolved organic carbon $(-0.60)$ & & \\
Total phosphorus (-0.62) & & \\
Sulfate (-0.63) & & \\
Conductivity (-0.66) & & \\
Chloride (-0.68) & & \\
\hline
\end{tabular}

On average, $43 \%$ of the individuals in each site were Ephemeroptera, Plecoptera or Trichoptera (EPTs). Diptera (mostly chironomids) and non-insects accounted for another 34\% and $13 \%$ of the individuals respectively. Coleoptera (8\%), and other insects $(2 \%)$ accounted for the remaining individuals. Average proportional abundances of non-insects and orders of insects did not change appreciably with deletion of rare taxa, but average richness was reduced to 42 taxa per site (range 12-68).

\section{>ASSEMBLAGE COMPOSITION AND ENVIRONMENTAL GRADIENTS}

For the OTU ordination, the scree test indicated that a 3 dimensional solution best represented the rank dissimilarity of sites. The 3-D ordination had a final stress of 18.5 and explained $67.4 \%$ of the variation in the dissimilarity matrix. Stresses of $<20$ are considered acceptable, with stresses approaching 20 being more acceptable in ordinations of large datasets (McCune and Grace, 2002). The majority of the variation was explained by axes 1 and 2 (33.9\% and $20.6 \%$ respectively), and a lesser amount (12.9\%) was explained by the third axis.

Axis 1 is related to the gradient in EPT richness and EPT proportional abundance (Table II). Correlations of Axis 1 scores with the relative abundances of individual taxa were not as strong as those with EPT metrics. Sites with low EPT richness and EPT proportional abundance (to the left on Axis 1) were those with high amounts of dissolved material in the water, predominantly pool/glide habitats and fine substrates. Increasing EPT richnesses and EPT proportional abundances were associated with decreasing ionic strength, and increasing fastwater (riffle, rapid, and cascade) habitat, stream slope, and substrate size. 
$\underline{A}$

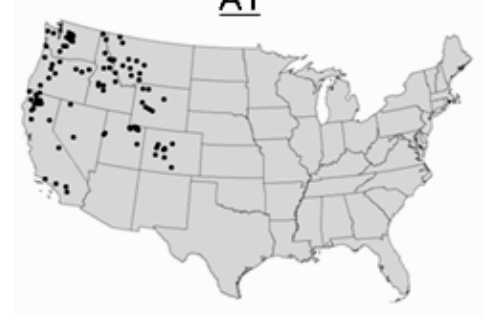

B1

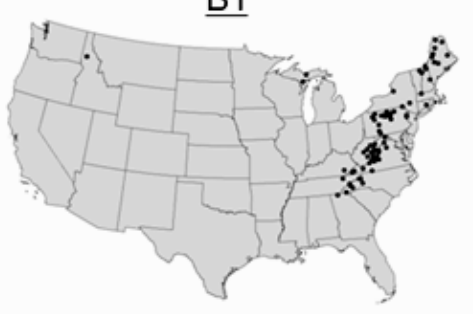

A2

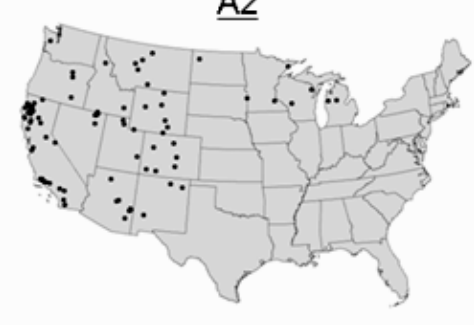

B2

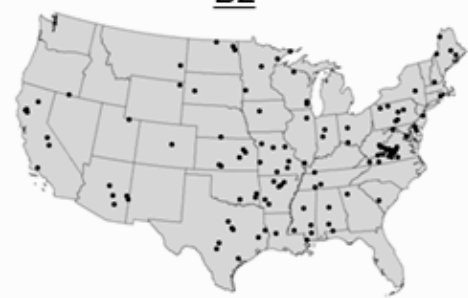

$\underline{\mathrm{C}}$
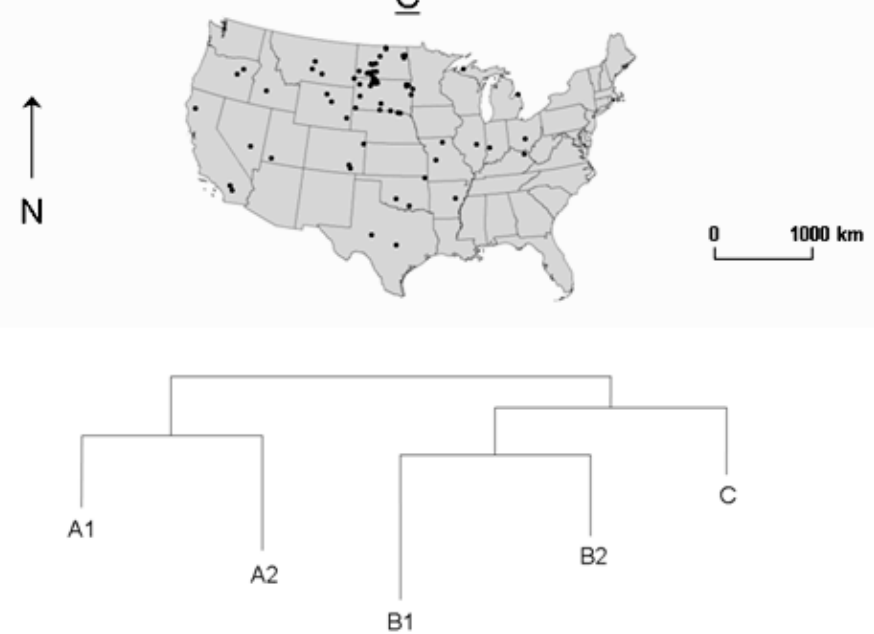

\section{Figure 1}

Map showing the spatial distribution of least-disturbed national wadeable stream sites in the assemblage-based groups from the cluster analysis. Groups were derived using macroinvertebrates identified to the finest practical level (OTUs) The pruned dendrogram from the cluster analysis is also shown.

Axis 2 is a longitude and elevation gradient separating western US sites from eastern US sites. Watershed area and summer air temperature are also correlated with assemblage composition but are not associated with one specific individual axis; watershed area is correlated with both Axes 1 and 3, and summer air temperature is correlated with Axes 1 and 2 (Table II).

\section{>DEFINING AND DESCRIBING ASSEMBLAGE-BASED GROUPS}

A minimum mean indicator taxon $p$-value occurred when sites were grouped into 5 clusters, indicating that this was a reasonable level at which to prune the dendrogram. The pruned dendrogram (Figure 1) shows that the 5 groups are part of 3 larger groups, indicated by the letters $A, B$, and $C$. Although the 5 groups were optimal in terms of indicator taxa, groups still had a great deal of internal heterogeneity. The mean within-group assemblage-based site 


\section{Table III}

Top three indicator taxa and indicator values from indicator species analysis using OTU assemblagebased groups. Groups are from cluster analysis of macroinvertebrate data from the national leastdisturbed site database.

\begin{tabular}{|l|c|c|c|}
\hline Group & Number of sites & Within-group similarity & Indicator taxa (Indicator value) \\
\hline A1 & 109 & 0.30 & $\begin{array}{c}\text { Zapada (73\%) } \\
\text { Drunella (67\%) } \\
\text { Rhyacophila }(61 \%)\end{array}$ \\
\hline A2 & 87 & 0.24 & $\begin{array}{c}\text { Zaitzevia (53\%) } \\
\text { Optioservus (42\%) } \\
\text { Micropsectra (40\%) }\end{array}$ \\
\hline B1 & 76 & 0.25 & $\begin{array}{c}\text { Leuctridae (59\%) } \\
\text { Dolophilodes (54\%) } \\
\text { Oulimnius (50\%) }\end{array}$ \\
\hline B2 & 115 & 0.20 & $\begin{array}{c}\text { Cheumatopsyche (47\%) } \\
\text { Stenelmis (44\%) } \\
\text { Stenonema (38\%) }\end{array}$ \\
\hline C & 70 & 0.19 & $\begin{array}{c}\text { Oligochaeta (55\%) } \\
\text { Caenis (50\%) } \\
\text { Dubiraphia (49\%) }\end{array}$ \\
\hline
\end{tabular}

similarity was only 0.24 (range: $0.19-0.30$ ). Despite the fact that assemblages were heterogeneous within groups, particular taxa were reasonably indicative of the groups (Table III). Taxa distinguishing groups were primarily genera.

We found that there was a degree of spatial organization to the assemblage-based groups (Figure 1). Sites in group A were predominantly in the western US. Group A1 sites were exclusively in the West and the eastern boundary of this group seems to correspond with the east slope of the Rocky Mountains. Most sites in group A2 were also in the western part of the country, but there were a handful of sites in the Upper Midwest as well. Group B sites were predominantly east of the Rocky Mountains. Group B1 sites were mostly confined to the Appalachian Mountains in the eastern US. Group B2 sites were much more dispersed, and although the largest concentration occurred east of the Rockies, there were several sites located in western states. Group C sites were concentrated in the upper Great Plains states of North and South Dakota, but scattered sites in this group spread from west of the Appalachian Mountains to the west coast states.

In terms of environmental and geographic variables, groups A1 and A2 were centered further west and sites were generally at higher altitudes than sites in other groups (Figure 2). Mean annual precipitation at sites in groups $\mathrm{A} 1$ and $\mathrm{A} 2$ was also more variable than that at sites in other groups. Group medians of watershed area, conductivity, \%fastwater habitat and substrate size showed consistent trends. Groups A1 and B1 and group C were on opposite ends of the spectrum for these variables, and groups A2 and B2 were intermediate. Groups A1 and B1 were groups with small watersheds (medians 18.1 and $22.4 \mathrm{~km}^{2}$ respectively) in areas of relatively high precipitation (917 and $1103 \mathrm{~mm}$ per year respectively). Sites in these groups generally had the lowest conductivities, greatest amount of fastwater habitat in study reaches and the coarsest substrates.

\section{>PREDICTING ASSEMBLAGE-BASED GROUP MEMBERSHIP}

A training CTA model was constructed using data from $67 \%$ of sites. The model was used to identify environmental and geographic variables that could best be used to distinguish the 5 assemblage-based cluster groups. The resulting CTA model (Figure 3) was based on longitude, chloride, precipitation, and \% fastwater habitat. The longitude at which CTA indicates the first break in classifying sites $\left(104.808^{\circ}\right)$ is approximately at the base of the east slope of the Rocky Mountains. Using data from the $33 \%$ of sites not used in constructing the training model, we found that $69.1 \%$ of sites were classified correctly by CTA. Sites in groups A1 and 

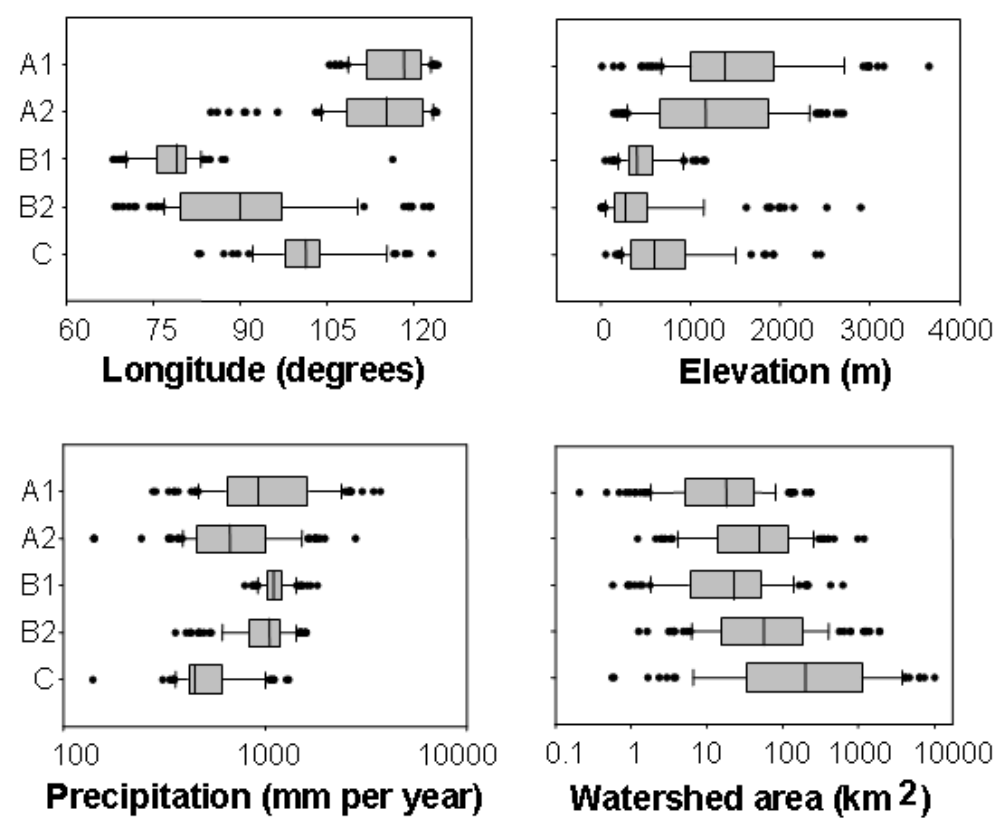

\section{Watershed area $\left(\mathrm{km}^{2}\right)$}
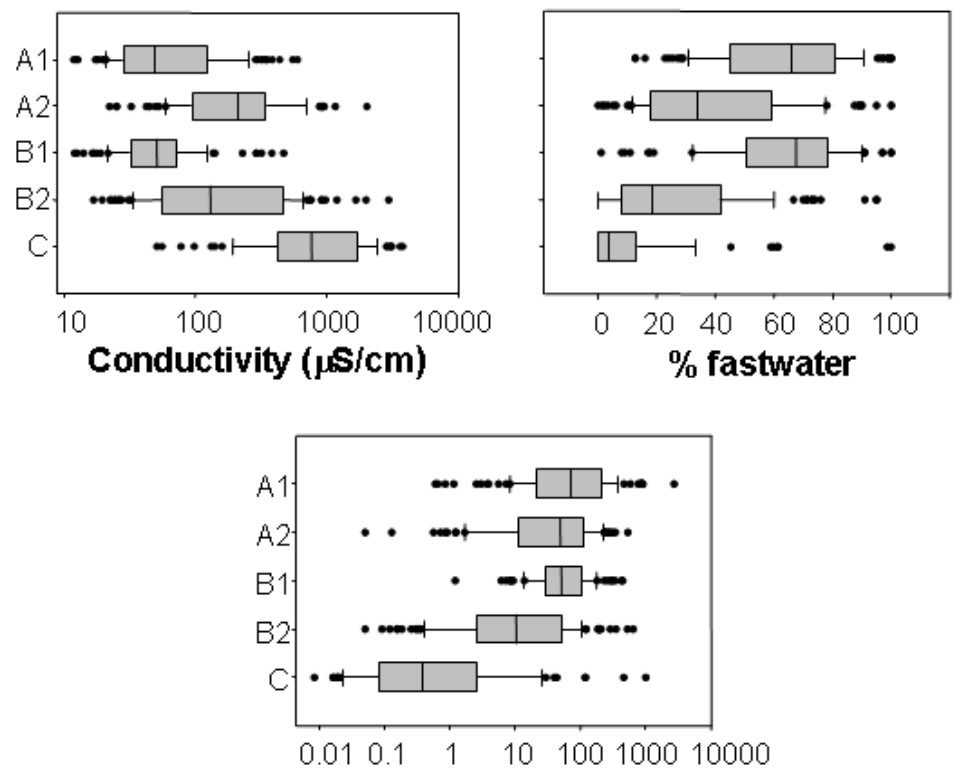

Mean substrate size $(\mathrm{mm})$

\section{Figure 2}

The environmental and geographic characteristics of least-disturbed national wadeable stream sites in the assemblage-based cluster analysis groups.

B1 were correctly classified most often ( $81 \%$ correctly classified), and sites in group A2 were the most difficult to place into their proper group (50.0\% correctly classified).

\section{> COMPARISONS OF OTU, TRAIT, AND COARSE TAXON PATTERNS}

Two pairs of assemblage-based groups (A1 and B1; A2 and B2) that were distinct based on OTUs were extremely similar in their central tendencies with respect to both coarse taxonomic groups and trait states (Figure 4, Table IV). Sites in these pairs of groups were generally separated geographically, but were otherwise similar with respect to several environmental 


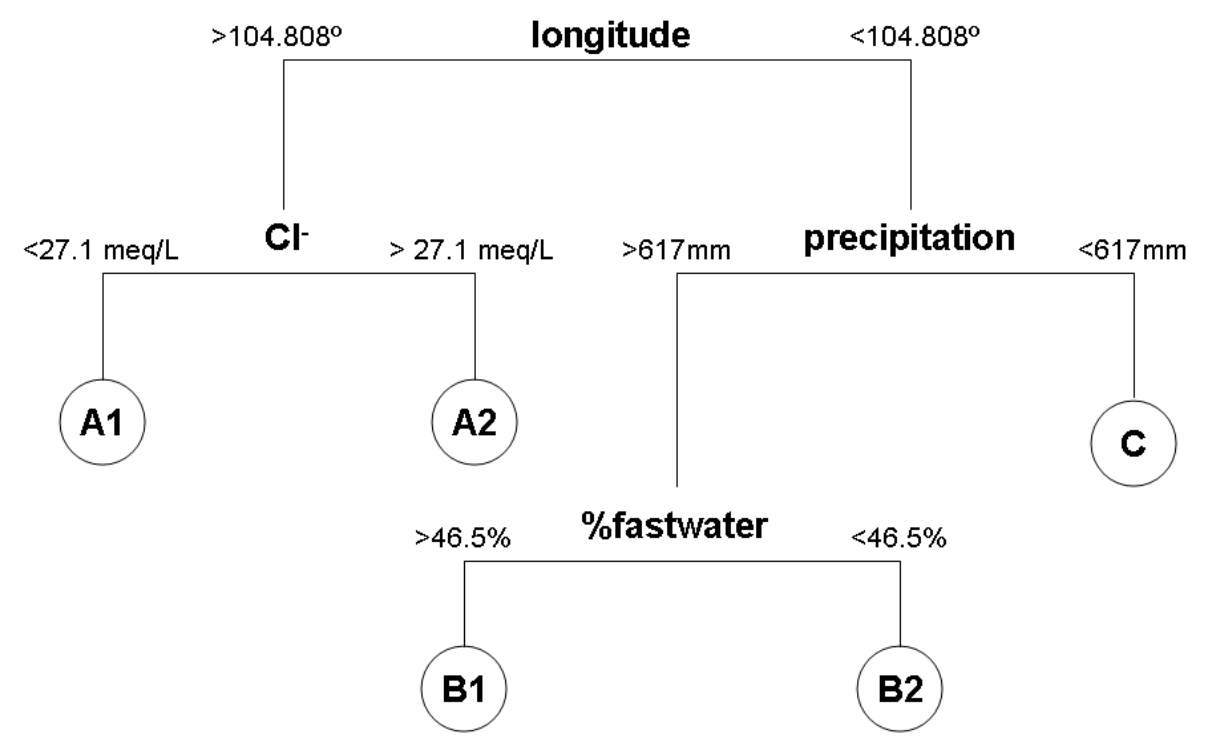

\section{Figure 3}

The five node classification tree that can be used to predict assemblage-based cluster group membership using environmental and geographic variables. OTU-based group IDs from cluster analysis are circled at the terminal tree nodes. Precipitation is average annual precipitation and \%fastwater is \%fastwater habitat in the sample reach. Group membership can be predicted by using the classification tree as a dichotomous key.

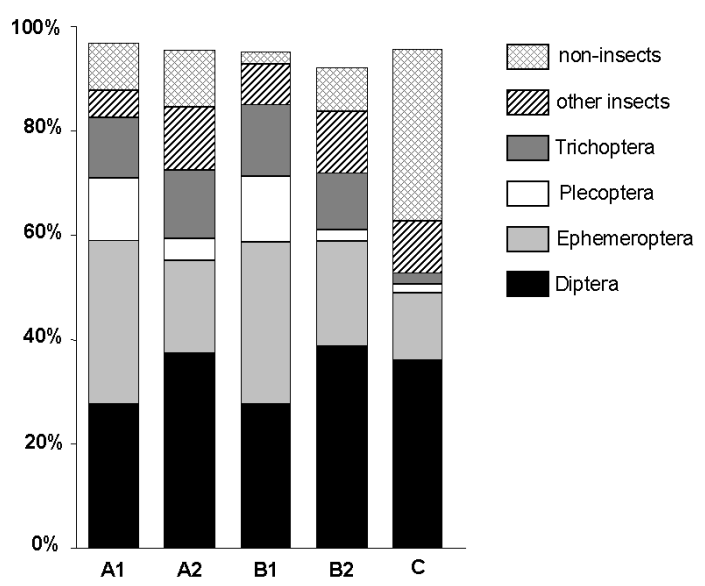

\section{Figure 4}

Mean proportional abundances of coarse macroinvertebrate categories in OTU assemblage-based groups. Groups are from cluster analysis of macroinvertebrate data from national least-disturbed site database. Stacked bars fall just short of $100 \%$ because of deletions of rare taxa.

variables (e.g. watershed area, conductivity, and \%fastwater; Figure 2). At coarse levels of taxonomic resolution, groups $\mathrm{A} 1$ and $\mathrm{B} 1$ had the highest \%EPT individuals, groups $\mathrm{A} 2$ and B2 had intermediate proportional abundances of EPT individuals, and Group $\mathrm{C}$ had the lowest \%EPT and the highest \%non-insects (Figure 4). With traits, groups A1 and B1 and group $\mathrm{C}$ were also generally on opposite ends of the gradient, with groups $\mathrm{A} 2$ and $\mathrm{B} 2$ in the middle (Table IV). Groups A1 and B1 assemblages were characterized by the high proportional abundances of univoltine, clinging invertebrates that are medium-sized to large at maturity. Group C sites had more smaller-bodied, multivoltine individuals that are adapted for living in depositional habitats.

For trait and coarse taxonomic group ordinations, scree tests indicated that a 2 dimensional NMS ordination solution best represented the rank dissimilarity of sites in terms of trait states, 
W.J. Gerth et al.: Knowl. Managt. Aquatic Ecosyst. (2013) 408, 02

\section{Table IV}

Median and interquartile ranges of the percentage of individuals possessing selected trait states from the OTU assemblage-based groups for least-disturbed sites in the contiguous US states.

\begin{tabular}{|l|c|c|c|c|c|}
\hline Trait state (Trait) & A1 & A2 & B1 & B2 & C \\
\hline Univoltine & 58.8 & 45.5 & 57.6 & 41.9 & 22.0 \\
(Voltinism) & $47.7-69.5$ & $34.1-56.7$ & $48.6-69.6$ & $32.7-49.4$ & $13.7-32.8$ \\
\hline Common in drift & 27.8 & 28.9 & 38.6 & 24.4 & 11.6 \\
(Occurrence in drift) & $21.8-35.6$ & $22.0-42.2$ & $32.3-45.9$ & $16.6-37.5$ & $3.9-20.8$ \\
\hline Streamlined & 26.8 & 17.8 & 23.0 & 11.6 & 4.7 \\
(Shape) & $17.9-39.2$ & $10.2-24.4$ & $16.8-33.6$ & $6.0-20.1$ & $2.4-10.9$ \\
\hline Medium to large at maturity & 32.3 & 20.8 & 42.4 & 22.2 & 6.4 \\
(Size at maturity) & $22.0-45.0$ & $13.4-32.6$ & $32.0-54.8$ & $14.2-33.7$ & $3.8-12.6$ \\
\hline Depositional & 11.0 & 25.1 & 14.8 & 37.9 & 70.7 \\
(Rheophily) & $6.1-16.7$ & $14.7-35.8$ & $7.9-23.2$ & $25.6-49.1$ & $51.4-81.2$ \\
\hline Cold / cool adapted & 40.4 & 18.1 & 17.9 & 7.3 & 3.0 \\
(Thermal preference) & $26.8-51.3$ & $11.7-25.4$ & $11.6-30.4$ & $2.8-13.1$ & $1.6-7.4$ \\
\hline Clingers & 46.6 & 32.3 & 43.3 & 30.7 & 13.8 \\
(Habit) & $35.2-56.2$ & $21.6-48.5$ & $32.4-55.1$ & $18.6-42.3$ & $6.6-25.6$ \\
\hline Collector-gatherers & 54.6 & 60.9 & 55.2 & 60.1 & 72.7 \\
(Trophic habit) & $45.5-67.3$ & $50.5-70.5$ & $44.9-64.8$ & $46.0-70.9$ & $54.0-81.3$ \\
\hline
\end{tabular}

whereas a 3 dimensional solution was best for the coarse taxa ordination. The 2-D traits ordination had a final stress of 17.8 and explained $87.1 \%$ of the variation in the dissimilarity matrix. The majority of the variation was explained by axis $1(69.4 \%)$, and a lesser amount (17.8\%) was explained by axis 2. The 3-D coarse taxa ordination had a final stress of 12.0 and explained $91.6 \%$ of the variation in the dissimilarity matrix. For this ordination axes 1 and 2 explained the majority of the variation ( $47.2 \%$ and $23.5 \%$ respectively), and a lesser amount (20.9\%) was explained by the third axis.

Figure 5 relates the environmental and geographic variables that were most strongly correlated with the first two ordination axes for each of the three NMS ordinations based on lowest practical level of taxonomic (OTU) resolution (Figure 5A), assemblage traits (Figure 5B), and a coarse level of taxonomic resolution (Figure $5 \mathrm{C}$ ). For each ordination, the arrangement of sites along Axis 1 progressed from sites with high proportions of slow water habitat, smaller substrate particles, and more dissolved constituents in the water to sites with more fastwater habitat, coarser substrates and fewer dissolved materials. The three ordinations, however, had some distinctions in their correlations with environmental/geographic variables. The fine taxa level (OTU level) ordination had the largest number of strong correlations with environmental variables $(|r|>0.45)$, and the coarse taxa ordination had the fewest; the traits ordination fell between these two. The coarse level and trait ordinations also had no environmental or geographic variables correlated with axis 2 . Axis 2 was correlated to longitude, elevation, and mean summer air temperature in the fine taxa level ordination (Figure 5A), all variables that distinguish the eastern and western US.

When looking at assemblage cluster group membership in the three ordination plots (data not shown), the five cluster groups were most distinct when overlaid on the fine taxa level ordination plot. Groups became much less distinct as data was converted to trait states or the taxonomic resolution was reduced. In the traits ordination, a very large proportion of the variation in the dissimilarity matrix could be explained along just one axis (Axis $1, R^{2}=0.69$ ), and all five assemblage cluster groups overlapped with each other considerably. In the coarse taxa ordination, 4 of the 5 assemblage cluster groups overlapped substantially. With the traits and coarse taxa ordinations, sites in A and B groups overlapped much more substantially than in the fine level ordination. In the coarse and trait ordinations, ordination axes were no longer related to east-west position within the US states (Figures $5 \mathrm{~B}$ and $\mathrm{C}$ ) which is one of the defining attributes of the difference between clusters $A$ and $B / C$ (Figure 4). 

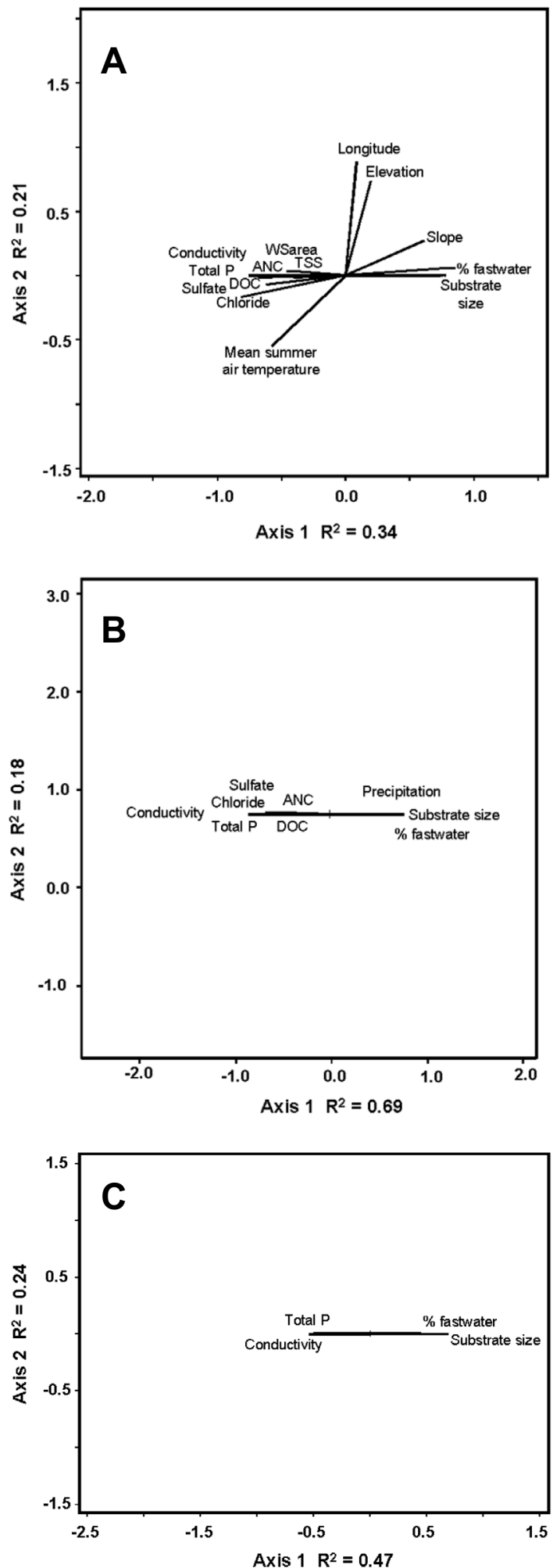

Figure 5

Relation of site data to the first 2 axes from nonmetric multidimensional scaling (NMS) ordinations based on (A) taxa identified to the lowest practical (OTU) level, (B) assemblage trait states, and (C) coarse level taxonomic groups from least-disturbed sites in the 48 contiguous US states. Symbols representing sites are not shown to improve legibility. Geographic and environmental variables with the strongest correlations with site coordinates $(r \mid>0.45)$ are shown as vector overlays. Lengths of vectors indicate the relative strengths of the correlations. 


\section{DISCUSSION}

For this study we used data from least-disturbed sites. Ideally, our analysis would have been conducted on totally pristine sites so our explorations of macroinvertebrate assemblages across the US would be based solely on natural factors. However, pristine reference sites that have not been disturbed in any way by anthropogenic activity do not exist. As a result, we were forced into accepting a least-disturbed definition of reference sites for our analyses. Problems arise with this approach, however, when definitions of what is considered least-disturbed vary across the landscape. In the US, it is much easier to find least-disturbed sites in mountainous ecoregions than lower gradient ecoregions due to their lower levels of overall human disturbance. Herlihy et al. (2008) examined the quality of reference sites in the WSA data we used in this analysis and did find variable reference site quality among the nine aggregate ecoregions in the survey. They used a regression approach to adjust reference expectations in ecoregions that showed a relationship between macroinvertebrate condition and human disturbance within reference sites. Four of the nine ecoregions did not require an adjustment but it was necessary in some of the Plains (Temperate Plains, Northern Plains, Southern Plains) and Mountainous (Western Mountains, Southern Appalachians) ecoregions. Even though we tried to eliminate human disturbance as a factor in our analyses, the fact that human disturbance is so pervasive at continental scales makes it impossible to completely eliminate it as a confounding factor. European researchers have struggled with the lack of pristine reference sites at a near-continental scale as well (Nijboer et al., 2004). Most recently they have also used data from least-disturbed sites (sites with good (class 4) or high (class 5) ecological quality) as reference sites (Verdonschot, 2006b) due to lack of good alternatives.

Our study looked at macroinvertebrate assemblages and physicochemical and geographic variables at least-disturbed sites spread fairly evenly across the 48 contiguous US states. No other study that we know of has considered macroinvertebrate - environment relationships over as large a spatial extent $\left(\sim 8000000 \mathrm{~km}^{2}\right)$. European Union studies, while somewhat smaller in scale, were the only studies near the same scale $\left(\sim 4500000 \mathrm{~km}^{2}\right)$, but coverage in these was less evenly spread across the study area (Verdonschot and Nijboer, 2004; Verdonschot, 2006b). Because perceptions about which environmental factors are most strongly related to assemblage composition depend in part on the spatial extent of observation (Marchant et al., 1999; Sandin and Johnson, 2004; Bonada et al., 2005; Johnson et al., 2007), we expected that we might find some consistencies and some differences between results of our study and those of other large-scale or national studies from elsewhere in the world. With ordinations based on invertebrates being identified to the finest practical level, we and others (Marchant et al., 1999; Turak et al., 1999; Heino et al., 2003; Lorenz et al., 2004; Sandin and Johnson, 2004) found a prominent relationship between invertebrate assemblage composition and geographic position (e.g. latitude and/or longitude). In our study and those from Australia (Marchant et al., 1999; Turak et al., 1999) assemblages varied primarily from east to west; in Germany (Lorenz et al., 2004) and Scandinavia (Heino et al., 2003; Sandin and Johnson, 2004) assemblages varied from north to south. On the other hand, Verdonschot (2006b) found that geographic position was not a good explanatory factor for invertebrate assemblage composition across the European Union. Other variables that were related to assemblage composition in our study and commonly highly correlated with assemblage composition in other large-scale studies were elevation, watershed area/stream size, substrate size, stream slope/water velocity, and a variety of water chemistry variables.

The second objective of our research was to classify sites into assemblage-based groups. Classification is a convenient tool, but putting sites into discrete groups is somewhat artificial, because assemblages vary continuously along environmental gradients (Marchant et al., 1999; Hawkins and Vinson, 2000; Sandin and Johnson, 2000; Heino et al., 2003). This was evident in our study as well in that OTU-based groups from cluster analysis overlapped on the fine level OTU-based ordination plot. Other problems with classification are that there are many classification methods to choose from and once the method is chosen it can 
often be hard to determine how many groups a set of sites should be placed into. Many studies use professional judgment or some other unspecified rule to determine how many assemblage-based groups to create (Furse et al., 1984; Smith et al., 1999; Turak et al., 1999; Heino et al., 2003). In contrast, we used an objective criterion, the minimum mean indicator taxon $p$-value, to determine the optimal number of groups. From this, we determined that when macroinvertebrates were identified to the finest practical level, least-disturbed wadeable stream sites from the contiguous US states could be placed into 5 groups. This is a small number of groups for the large area covered and there was considerable assemblage heterogeneity within groups (mean within-group similarity $=0.24$ ). Because of this, our assemblagebased groups may be too coarse for predictive modeling, where it is important to specify site-types and their assemblages as accurately and precisely as possible (Hawkins et al., $2000 b)$. On the other hand, group membership was reasonably predictable by CTA with geographic and environmental variables (69.1\% correctly classified). Although direct comparison among studies is problematic because the percent correctly classified is influenced by the total number of groups being predicted and the taxonomic resolution used (Furse et al., 1984), our values were similar to Furse et al. (1984) and Smith et al. (1999) or better than Heino et al. (2003). Indicator values for the strongest indicator taxa were also reasonably high, and higher than those found in a Finnish study (Heino et al., 2003). As with ordination, geographic position was a predictor of group membership in our study as well as in other large-scale studies in Europe and Australia (Smith et al., 1999; Turak et al., 1999; Heino et al., 2003). Other predictor variables were not as consistent among other studies (Furse et al., 1984; Smith et al., 1999; Turak et al., 1999; Heino et al., 2003).

The importance of geography in our study is likely due to the distinctive taxa pools found in the eastern and western parts of the contiguous US states. While the distribution patterns of individual taxa vary from those occurring in only small geographic regions to those that are transcontinental, many appear to only occur in either the eastern or western US. For example, there are many distinctive stonefly (Plecoptera) genera confined to either the eastern or western North American mountain systems (Stewart and Stark, 2002). Distinct eastern and western mayfly (Ephemeroptera) faunas are also evident (Randolph, 2002). Distribution patterns of other North American aquatic macroinvertebrates are less well documented. Current distribution patterns of aquatic macroinvertebrates are a result of dispersal, isolation, extinction, and speciation of taxa in the past. A study classifying lotic freshwater fish assemblages across the 48 contiguous US states (Herlihy et al., 2006) noted a similar distinction of eastern and western freshwater fish faunas and explained the development of these faunas by land mass movements, climatic oscillations, and mountain uplifts that occurred in the geologic past.

\section{> COMPARISONS USING OTUS, TRAITS, AND COARSE TAXA}

One of the reasons we wanted to examine invertebrate patterns from least-disturbed sites across such a large spatial area was to determine if assemblage-types were convergent when traits or coarse taxonomic groups were used rather than mostly genus-based OTUs. Convergence would be indicated if groups of sites with distinctive OTU compositions, but similar environmental characteristics, nonetheless had similar trait and/or coarse taxa compositions. Convergence of groups from geographically distinct regions with similar environmental conditions would indicate that characteristics of assemblage-types can be predicted from environmental variables and that key, repeated combinations of environmental variables lead to assemblages with similar characteristics in many parts of the world (Lamouroux et al., 2002). In our study, we used OTU relative abundance data in cluster analysis and indicator species analysis to find groups of sites that were optimally distinguished by indicator taxa, and looked for convergence of these OTU-based groups. This was a unique approach among studies examining taxonomic and functional patterns in streams over broad spatial extents. In contrast, a study looking for convergence of freshwater fish assemblages from Europe and North America identified an environmental gradient that fish assemblages appear to respond to at small scales in France and looked for a similar assemblage trait composition response to this environmental gradient in the US state of Virginia (Lamouroux et al., 2002). 
In another freshwater fish study in North America and a macroinvertebrate study in leastdisturbed stream sites in Finland, OTU compositions and assemblage trait patterns were examined to determine if OTU analyses reflected a greater importance of geographic and regional environmental variables than trait analyses did, but in neither case was classification performed looking for natural OTU assemblage groups that might be convergent when trait data were used (Heino et al., 2007; Hoeinghaus et al., 2007). With our analyses, we found that two pairs of cluster groups ( $\mathrm{A} 1$ and $\mathrm{B} 1$, and $\mathrm{A} 2$ and $\mathrm{B} 2$ ) were remarkably similar in their central tendencies for traits and coarse taxonomic groups. Ordinations using trait and coarse taxonomic data also both showed convergence (i.e. substantial overlap) of these same OTUbased groups, and lack of correlation with longitude, which was highly correlated with assemblage composition in the ordination using OTU data. However, trait and coarse taxa ordinations also showed greater homogenization of OTU-based cluster groups in general (not only the two pairs of groups with potentially differing regional species pools), and a reduction in the number of strong correlations with environmental variables, especially with the coarse taxa analysis.

Essential to our traits analysis was the choice of traits that were among the least intercorrelated and least phyologenetically constrained. Thus trends in these traits in relation to environmental factors should be most generalizable over broad geographic areas. Comparing OTU and functional compositions, we found that as expected OTU composition was related to geographic coordinates (longitude), but functional composition was insensitive to this variable. However, relationships between OTU assemblage composition and other environmental factors were not obscured by relationships with geographic coordinates. In fact, OTU composition and functional composition were largely related to similar environmental factors, and OTU composition was even correlated with a few more environmental variables than functional composition was. The only other stream macroinvertebrate study we are aware of that compares functional and OTU compositions in least-disturbed sites over a large area is one from Finland (Heino et al., 2007). They also used least constrained traits to characterize functional composition, but only used 3 traits. In their study, as in ours, taxonomic and trait composition patterns were correlated with the similar environmental variables, but in contrast to our findings, in Finland both taxa and traits showed weak relationships with geographic coordinates. The lack of differences between the correlations of geographic variables with taxonomic and functional compositions are most likely due to the smaller spatial extent of the study ( $305000 \mathrm{~km}^{2}$ versus $\sim 8000000 \mathrm{~km}^{2}$ in our study) and the fact that species pools are rather similar across Scandinavian ecoregions (Sandin and Johnson, 2000; Heino et al., 2007). If the distributions of taxa in species pools are not much more restricted than the scale of observation, taxonomic composition patterns will be weakly or uncorrelated with spatial variables (Hoeinghaus et al., 2007).

Ours is the first study that we know of that examined convergence of cluster analysis groups when taxonomic resolution was reduced from primarily genus level to order and coarser levels. Although not previously examined, it makes some sense that such a reduction in taxonomic resolution would result in convergence while preserving correlations with several environmental variables highly correlated with OTU assemblage composition. Convergence of OTU-based assemblage groups that are differentiated by east-west position probably occurs because many genera of aquatic macroinvertebrates are found only in the eastern or western portion of the contiguous US (Randolph, 2002; Stewart and Stark, 2002), whereas, the distributions of the 6 coarse taxonomic groups we used are not limited in this way. In addition, similar correlations of OTU-based and coarse taxa assemblage composition with environmental variables (other than geographic position) make sense because in general there is greater similarity in environmental tolerances and taxon traits among taxa within orders than among the aquatic macroinvertebrate orders themselves (Bailey et al., 2001; Poff et al., 2006). However, decreasing the taxonomic resolution from mainly genus-level to order and coarser did result in fewer strong correlations between assemblage composition and environmental variables (Figure $5 \mathrm{C}$ ) and a convergence of many of the OTU-based cluster groups, not only those occurring primarily in the eastern and western parts of the country. A similar reduction in the number of strong correlations between assemblage composition and environmental 
variables was generally observed as taxonomic resolution was reduced from species through order levels in watersheds contributing to New York City's drinking water supply (Arscott et al., 2006). This reduction in correlations was particularly pronounced in watersheds west of the Hudson River where anthropogenic influences were less common.

\section{> IMPLICATIONS OF STUDYING MACROINVERTEBRATE PATTERNS AT VERY LARGE SCALES}

In our study we examined near-natural macroinvertebrate composition patterns and relationships with environmental and geographic variables in wadeable streams over the largest spatial extent considered to date. Assemblage composition patterns using OTU data were related to both biogeographic patterns, reflecting differing taxon pools in the eastern and western parts of the contiguous US states, and environmental factors related to the gradient from mountain to lowland streams. These findings give context to other studies that take place in the US, and provide an impetus for studies searching for similar patterns in other parts of the world. Least-disturbed sites sampled in the contiguous US states in the future could also be placed into 1 of the 5 cluster groups we developed with reasonable confidence using environmental measurements and geographic coordinates, and even though our cluster groups have considerable internal heterogeneity, general expectations of assemblage composition could be drawn. Further classification of sites within our 5 groups would also be possible if it were desirable to define stream types with more homogenous assemblages for bioassessment purposes.

Because our study covered so large a spatial extent, we were also able to investigate whether there were more generalizable patterns that were insensitive to differing taxa pools. In contrast to OTU composition, trait and coarse taxa composition patterns were not correlated with geographic coordinates. In addition, when considering central tendencies, OTU-based cluster groups with potentially differing taxa pools that had sites with similar environmental characteristics appeared convergent in trait and coarse taxa compositions. Although more general, use of traits and amalgamating OTU data into coarse taxonomic groups did not otherwise add to our understanding of macroinvertebrate-environment relationships.

\section{ACKNOWLEDGEMENTS}

This work was funded by cooperative agreement CR831682-01 between Oregon State University and the US Environmental Protection Agency. We thank all the people involved with the EMAP-West and the National Wadeable Streams Assessment for their insights and for sharing data. We also thank Scott Miller for his thoughts on trait analyses, and Guillermo Giannico for advice on ordination graph formatting.

\section{REFERENCES}

Arscott D.B., Jackson J.K. and Kratzer E.B., 2006. Role of rarity and taxonomic resolution in regional and spatial analysis of stream macroinvertebrates. J. North Am. Benthol. Soc., 25, 977-997.

Bailey R.C., Norris R.H. and Reynoldson T.B., 2001. Taxonomic resolution of benthic macroinvertebrate communities in bioassessments. J. North Am. Benthol. Soc., 20, 280-286.

Bonada N., Zamora-Munoz C., Rieradevall M. and Prat N., 2005. Ecological and historical filters constraining spatial caddisfly distribution in Mediterranean rivers. Freshwater Biol., 50, 781-797.

Cao Y., Bark A.W. and Williams W.P., 1996. Measuring the response of macroinvertebrate communities to water pollution: a comparison of multivariate approaches, biotic and diversity indices. Hydrobiologia, 341, 1-19.

Daly C., Gibson W.P., Taylor G.H., Johnson G.L. and Pasteris P., 2002. A knowledge-based approach to the statistical mapping of climate. Climate Res., 22, 99-113.

Dufrêne M. and Legendre P., 1997. Species assemblages and indicator species: the need for a flexible asymmetrical approach. Ecol. Monogr., 67, 345-366. 
Furse M.T., Moss D., Wright J.F. and Armitage P.D., 1984. The influence of seasonal and taxonomic factors on the ordination and classification of running-water sites in Great Britain and on the prediction of their macroinvertebrate communities. Freshwater Biol., 14, 257-280.

Furse M.T., Hering D., Moog O., Verdonschot P., Johnson R.K., Brabec K., Gritzalis K., Buffagni A., Pinto P., Friberg N., Murray-Bligh J., Kokes J., Alber R., Usseglio-Polatera P., Haase P., Sweeting R., Bis B., Szoszkiewicz K., Soszka H., Springe G., Sporka F. and Krno I., 2006. The STAR project: context, objectives and approaches. Hydrobiologia, 566, 3-29.

Hawkins C.P. and Vinson M.R., 2000. Weak correspondence between landscape classifications and stream invertebrate assemblages: implications for bioassessment. J. North Am. Benthol. Soc., 19, 501-517.

Hawkins C.P., Norris R.H., Gerritsen J., Hughes R.M., Jackson S.K., Johnson R.K. and Stevenson R.J., 2000a. Evaluation of the use of landscape classifications for the prediction of freshwater biota: synthesis and recommendations. J. North Am. Benthol. Soc., 19, 541-556.

Hawkins C.P., Norris R.H., Hogue J.N. and Feminella J.W., 2000b. Development and evaluation of predictive models for measuring the biological integrity of streams. Ecol. Appl., 10, 1456-1477.

Heino J., Muotka T., Myrkä H., Paavola R., Haemaelaeinen H. and Koskenniemi E., 2003. Defining macroinvertebrate assemblage types of headwater streams: Implications for bioassessment and conservation. Ecol. Appl., 13, 842-852.

Heino J., Myrkä H., Kotanen J. and Muotka T., 2007. Ecological filters and variability in stream macroinvertebrate communities: do taxonomic and functional structure follow the same path? Ecography, 30, 217-230.

Herlihy A.T., Larsen D.P., Paulsen S.G., Urquhart N.S. and Rosenbaum B.J., 2000. Designing a spatially balanced, randomized site selection process for regional stream surveys: the EMAP mid-Atlantic pilot study. Environ. Monitoring Assess., 63, 95-113.

Herlihy A.T., Hughes R.M. and Sifneos J.C., 2006. Landscape clusters based on fish assemblages in the conterminous USA and their relationship to existing landscape classifications. In: Hughes, R.M., Wang L. and Seelbach P.W. (eds.), Landscape Influences on Stream Habitats and Biological Assemblages. Symposium 48. American Fisheries Society, Bethesda, Maryland, 87-112.

Herlihy A.T., Paulsen S.G., Van Sickle J., Stoddard J.L., Hawkins C.P. and Yuan L.L., 2008. Striving for consistency in a national assessment: the challenges of applying a reference-condition approach at a continental scale. J. North Am. Benthol. Soc., 27, 860-877.

Hoeinghaus D.J., Winemiller K.O. and Bimbaum J.S., 2007. Local and regional determinants of stream fish assemblage structure: inferences based on taxonomic vs. functional groups. J. Biogeogr., 34, 324-338.

Johnson R.K., Furse M.T., Hering D. and Sandin L., 2007. Ecological relationships between stream communities and spatial scale: implications for designing catchment-level monitoring programmes. Freshwater Biol., 52, 939-958.

Klemm D.J., Blocksom K.A., Fulk F.A., Herlihy A.T., Hughes R.M., Kaufmann P.R., Peck D.V., Stoddard J.L. and Thoeny W.T. 2003. Development and evaluation of a macroinvertebrate biotic integrity index (MBII) for regionally assessing Mid-Atlantic Highlands streams. Environ. Manage. 31, 656-669.

Kruskal J.B. and Wish M., 1978. Multidimensional scaling, Sage Publications, Beverly Hills, CA.

Lamouroux N., Poff N.L. and Angermeier P.L., 2002. Intercontinental convergence of stream fish community traits along geomorphic and hydraulic gradients. Ecology, 83, 1792-1807.

Lenat D.R. and Resh V.H., 2001. Taxonomy and stream ecology - the benefits of genus- and specieslevel identifications. J. North Am. Benthol. Soc., 20, 297-298.

Lorenz A., Feld C.K. and Hering D., 2004. Typology of streams in Germany based on benthic invertebrates: ecoregions, zonation, geology and substrate. Limnologica, 34, 379-389.

Malmqvist B, 2002. Aquatic invertebrates in riverine landscapes. Freshwater Biol., 47, 679-694.

Marchant R., Hirst A., Norris R. and Metzeling L., 1999. Classification of macroinvertebrate communities across drainage basins in Victoria, Australia: Consequences of sampling on a broad spatial scale for predictive modelling. Freshwater Biol., 41, 253-268.

McCune B, 1994. Improving community analysis with the Beals smoothing function. Ecoscience, 1, 82-86.

McCune B. and Grace J.B., 2002. Analysis of Ecological Communities, MjM Software Design, Gleneden Beach, Oregon.

Merritt R.W., Cummins K.W. and Berg M.B., 2008. An Introduction to the Aquatic Insects of North America. 4th edition, Kendall/Hunt Publishing, Dubuque, lowa.

Nijboer R.C., Johnson R.K, Verdonschot P.F.M., Sommerhäuser M. and Buffagni A., 2004. Establishing reference conditions for European streams. Hydrobiologia, 516, 91-105. 
Peck D.V., Herlihy A.T., Hill B.H., Hughes R.M., Kaufmann P.R., Klemm D.J., Lazorchak J.M., McCormick F.H., Peterson S.A., Ringold P.L., Magee T. and Cappaert M.R., 2006. Environmental Monitoring and Assessment Program - Surface Waters Western Pilot Study: field operations manual for wadeable streams, EPA 620/R-06/003, U.S. Environmental Protection Agency, Office of Research and Development, Washington, DC.

Poff N.L., 1997. Landscape filters and species traits: Towards mechanistic understanding and prediction in stream ecology. J. North Am. Benthol. Soc., 16, 391-409.

Poff N.L., Olden J.D., Vieira N.K.M., Finn D.S., Simmons M.P. and Kondratieff B.C., 2006. Functional trait niches of North American lotic insects: traits-based ecological applications in light of phylogenetic relationships. J. North Am. Benthol. Soc., 25, 730-755.

Ramsey F.I. and Schafer D.W., 2002. The Statistical Sleuth, Duxbury Press, Belmont, California.

Randolph R.P., 2002. Atlas and Biogeographic Review of the North American Mayflies (Ephemeroptera), Purdue University, Ann Arbor, MI.

Sandin L. and Johnson R.K., 2000. Ecoregions and macroinvertebrate assemblages of Swedish streams. J. North Am. Benthol. Soc., 19, 462-474.

Sandin L. and Johnson R.K., 2004. Local, landscape and regional factors structuring benthic macroinvertebrate assemblages in Swedish streams. Land. Ecol., 19, 501-514.

Smith M.J., Kay W.R., Edward D.H.D., Papas P.J., Richardson K.S.J., Simpson J.C., Pinder A.M., Cale D.J., Horwitz P.H.J., Davis J.A., Yung F.H., Norris R.H. and Halse S.A., 1999. AusRivAs: using macroinvertebrates to assess ecological condition of rivers in Western Australia. Freshwater Biol., $41,269-282$.

Stevens D.L. and Olsen A.R., 2004. Spatially balanced sampling of natural resources. J. Amer. Stat. Assoc., 99, 262-278.

Stewart K.W. and Stark B.P., 2002. Biogeography of nearctic Plecoptera. In: Nymphs of North American Stonefly Genera (Plecoptera), 2nd edition, The Caddis Press, Columbus, Ohio, 16-22.

Stoddard J.L., Peck D.V., Paulsen S.G., Van Sickle J., Hawkins C.P., Herlihy A.T., Hughes R.M., Kaufmann P.R., Larsen D.P., Lomnicky G., Olsen A.R., Peterson S.A., Ringold P.L. and Whittier T.R., 2005. An ecological assessment of western streams and rivers, EPA 620/R-05/005, US Environmental Protection Agency, Washington, DC.

Stribling J.B., Pavlik K.L., Holdsworth S.M. and Leppo E.W., 2008. Data quality, performance, and uncertainty in taxonomic identification for biological assessments. J. North Am. Benthol. Soc., 27, 906-919.

Thorp J.H. and Covich A.P., 2001. Ecology and Classification of North American Freshwater Invertebrates, 2nd edition, Academic Press, New York.

Turak E., Flack L.K., Norris R.N., Simpson J. and Waddell N., 1999. Assessment of river condition at a large spatial scale using predictive models. Freshwater Biol., 41, 283-298.

Verdonschot, P.F.M., 2006a. Data composition and taxonomic resolution in macroinvertebrate stream typology. Hydrobiologia, 566, 59-74.

Verdonschot P.F.M., 2006b. Evaluation of the use of Water Framework Directive typology descriptors, reference sites and spatial scale in macroinvertebrate stream typology. Hydrobiologia, 566, 39-58.

Verdonschot P.F.M. and Nijboer R.C., 2004. Testing the European stream typology of the Water Framework Directive for macroinvertebrates. Hydrobiologia, 516, 35-54.

Waite I.R., Herlihy A.T., Larsen D.P. and Klemm D.J., 2000. Comparing strengths of geographic and nongeographic classifications of stream benthic macroinvertebrates in the Mid-Atlantic Highlands, USA. J. North Am. Benthol. Soc., 19, 429-441.

Whittier T. R., Stoddard J.L., Larsen D.P. and Herlihy A.T., 2007. Selecting reference sites for stream biological assessments: best professional judgment or objective criteria. J. North Am. Benthol. Soc., 26, 349-360.

Wright J.F., Moss D., Armitage P.D. and Furse M.T., 1984. A preliminary classification of running-water sites in Great Britain based on macro-invertebrate species and the prediction of community type using environmental data. Freshwater Biol., 14, 221-256. 